\title{
Tensões diante dos conflitos entre demandas do mundo do trabalho e da reprodução social no Brasil: a relevância do trabalho doméstico remunerado e do trabalho feminino
}

\author{
Tensions in the face of conflicts between demands from the world of work and social \\ reproduction in Brazil: the relevance of paid domestic work and female work
}

\author{
Francilene Soares de Medeiros Costa* \\ Tiago Barreto de Andrade Costa**
}

\begin{abstract}
Resumo
Dados da OIT evidenciam a importância quantitativa do Brasil no mercado de trabalho doméstico remunerado no mundo. Esssa realidade pode ser associada às formas como se tem enfrentado no Brasil as tensões decorrentes dos conflitos entre as demandas do mundo do trabalho face às demandas da esfera da reprodução social. Indica-se que os sistemas de proteção social, estatal e empresarial ainda atuam de forma incipiente no enfretamento desta realidade nacional. Por sua vez, as famílias assumem as responsabilidades desenvolvendo estratégias diferenciadas, conforme a sua posição de classe social. Dessa maneira, evidencia-se que o trabalho da mulher e do trabalho doméstico remunerado tem uma importância fundamental na reprodução deste padrão.
\end{abstract}

Palavras-chave: Trabalho doméstico remunerado. Trabalho feminino. Trabalho produtivo. Reprodução social.

\begin{abstract}
ILO data show the quantitative importance of Brazil in the paid domestic labor market in the world. This reality can be associated with the ways in which the tensions arising from the conflicts between the demands of the world of work and the demands of the sphere of social reproduction have been faced in Brazil. It is indicated that the state and corporate social protection systems still act in an incipient way in facing this national reality. In turn, families assume responsibilities by developing different strategies according to their social class position. Thus, it is evident that women's work and paid domestic work are of fundamental importance in reproducing this pattern.
\end{abstract}

Keywords: Paid domestic work. Female work. Productive work. Social reproduction.

\footnotetext{
* Professora adjunta da Faculdade de Serviço Social da Universidade Federal do Pará. Assistente social. Doutora em Geografia pela FCT- Unesp.

** Professor adjunto da Faculdade de Geografia e Cartografia da Universidade Federal do Pará. Geógrafo. Doutor em Geografia pela FCT- Unesp.
} 


\section{Introdução}

Em todo o mundo, o trabalho doméstico remunerado tem sido uma oportunidade de emprego para milhões de pessoas. Nos últimos anos, o debate sobre as relações e as condições em que se realiza o trabalho doméstico remunerado tem adquirido relevância e entrado nas pautas do debate público, dadas as más condições de trabalho e o histórico de preconceito, estigma e invisibilidade social que tem sido sua marca em vários lugares, assumindo, certamente, as particularidades do contexto sócio histórico de cada país. Também, se faz presente o debate tanto do ponto de vista da sua participação nas estratégias de resolução dos conflitos entre trabalho e vida familiar, quanto da representatividade da população trabalhadora mundial ocupada em tais serviços ${ }^{1}$.

De acordo com o Artigo 10 da Convenção sobre o Trabalho Decente para as Trabalhadoras e os Trabalhadores Domésticos, no 189 (OIT, 2011), o termo "trabalho doméstico" refere-se ao trabalho realizado de forma remunerada por uma pessoa em uma ou para uma ou mais famílias. Os trabalhadores domésticos remunerados não formam um conjunto homogêneo, não somente no que diz respeito ao perfil demográfico, mas também no que se refere às possibilidades de ocupação, tarefas ou atividades que podem realizar tais como faxina ou limpeza, cuidar de crianças, pessoas idosas ou portadoras de necessidades especiais, ser vigia, cozinhar, cuidar de jardim, dentre outras. Assim, para a OIT, embora tarefas específicas e o tipo de empregador possam mudar de país para país, o que está no centro da definição de trabalho doméstico é fato do local de trabalho corresponder a um ambiente privado e doméstico.

De acordo com estimativas e levantamentos da OIT publicadas no documento denominado "Domestic workers across the world: global and regional statistics and the extent of legal protection" (ILO, 2013), a demanda por serviços domésticos remunerados tem aumentado em todo o mundo nas últimas duas décadas. Entre os anos de 1995 e $2010^{2}$, o número de pessoas ocupadas nesses serviços passou de 33,2 milhões para 52,6 milhões (ILO, 2013) e, conforme publicação mais recente, esse número já pode chegar a 67,1 milhões (ILO,

\footnotetext{
${ }^{1}$ Esse movimento está contido, de forma mais ampla, na atuação da OIT no sentido da construção da agenda de trabalho decente, que é uma expressão que sintetiza a perspectiva da organização acerca de aspectos que podem apontar para a melhoria das condições de trabalho vivenciada pelos diversos trabalhadores nas mais diferentes ocupações em todo o mundo. As quatro áreas da Agenda de Trabalho Decente da OIT são os direitos do trabalho; emprego; segurança e proteção social e direito de voz e representação (OIT, 2005).

2 Ou anos aproximados, a depender da disponibilidade de dados e estatísticas de cada país (ILO, 2013).
} 
Tensões diante dos conflitos entre demandas do mundo do trabalho e da reprodução social...

2016). Desses quantitativos, estima-se que aproximadamente $80 \%$ sejam mulheres.

A publicação (ILO, 2013), revela o volume estimado de trabalhadores domésticos remunerados com base em dados de 117 países e territórios ${ }^{3}$. No estudo, esses países e territórios foram organizados em 6 agrupamentos regionais, denominados pela Organização da seguinte forma: "países desenvolvidos", "Leste Europeu e Comunidade dos Estados Independentes (CIS)", "Ásia e o Pacífico", "América Latina e Caribe", "África" e "Oriente Médio". Essa regionalização dos países, em grande medida, segue a linha de trabalho de campo da OIT e replica com poucas variações a metodologia empregada no documento Global Wage Report 2010/11 (ILO, 2010). Os países correspondentes a cada grupamento encontramse listados no Erro! Fonte de referência não encontrada.:

Figura 1 - Agrupamento regional de países, segundo classificação da OIT

\begin{tabular}{|ll|}
\hline Region & Countries and territories \\
\hline Developed countries & $\begin{array}{l}\text { Australia, Austria, Belgium, Canada, Cyprus, Denmark, Finland, France, Germany, Greece, } \\
\text { Iceland, Ireland, Israel, Italy, Japan, Republic of Korea, Luxemburg, Malta, Netherlands, } \\
\text { New Zealand, Norway, Portugal, Singapore, Spain, Sweden, Switzerland, United Kingdom, } \\
\text { United States of America }\end{array}$ \\
\hline $\begin{array}{l}\text { Eastern Europe } \\
\text { and Commonwealth } \\
\text { of Independent States } \\
\text { (CIS) }\end{array}$ & $\begin{array}{l}\text { Albania, Armenia, Azerbaijan, Belarus, Bosnia and Herzegovina, Bulgaria, Croatia, Czech } \\
\text { Republic, Estonia, Georgia, Hungary, Kazakhstan, Kyrgyzstan, Latvia, Lithuania, Republic of } \\
\text { Asia and the Pacific } \\
\text { former Yugoslav, Republic of Macedonia, Turkey, Turbmenistan, Ukraine, Uzbekistan, The }\end{array}$ \\
\hline $\begin{array}{l}\text { Afghanistan, Bangladesh, Bhutan, Brunei Darussalam, Cambodia, China, Fiji, Hong Kong } \\
\text { (China), India, Indonesia, Iran, Democratic Republic of Korea, Lao People's Democratic }\end{array}$ \\
$\begin{array}{l}\text { Republic, Macau (China), Malaysia, Maldives, Mongolia, Myanmar, Nepal, Pakistan, Papua } \\
\text { New Guinea, Philippines, Solomon Islands, Sri Lanka, Thailand, Timor-Leste, Viet Nam }\end{array}$ \\
\hline $\begin{array}{l}\text { Argentina, Bahamas, Barbados, Belize, Plurinational State of Bolivia, Brazil, Chile, } \\
\text { and the Caribbean } \\
\text { Colombia, Costa Rica, Cuba, Dominican Republic, Ecuador, El Salvador, Guadeloupe, } \\
\text { Guatemala, Guyana, Haiti, Honduras, Jamaica, Martinique, Mexico, Netherlands Antilles, } \\
\text { Nicaragua, Panama, Paraguay, Peru, Puerto Rico, Suriname, Trinidad and Tobago, Uruguay, } \\
\text { Bolivarian Republic of Venezuela }\end{array}$ \\
\hline $\begin{array}{l}\text { Algeria, Angola, Benin, Botswana, Burkina Faso, Burundi, Cameroon, Cape Verde, Central } \\
\text { African Republic, Chad, Comoros, Congo, Democratic Republic of Congo, Cote d'Ivoire, Egypt, } \\
\text { Equatorial Guinea, Eritrea, Ethiopia, Gabon, Gambia, Ghana, Guinea, Guinea-Bissau, Kenya, } \\
\text { Lesotho, Liberia, Libya, Madagascar, Malawi, Mali, Mauritania, Mauritius, Morocco, Mozambique, } \\
\text { Namibia, Niger, Nigeria, Reunion, Rwanda, Senegal, Sierra Leone, Somalia, South Africa, Sudan, } \\
\text { Swaziland, United Republic of Tanzania, Togo, Tunisia, Uganda, Zambia, Zimbabwe }\end{array}$ \\
\hline $\begin{array}{l}\text { Bahrain, Iraq, Jordan, Kuwait, Lebanon, Occupied Palestinian Territory, Oman, Qatar, Saudi } \\
\text { Arabia, Syrian Arab Republic, United Arab Emirates, Yemen }\end{array}$ \\
\hline
\end{tabular}

Fonte: ILO (2013).

\footnotetext{
${ }^{3}$ Esses dados foram principalmente recuperados de publicações oficiais, tais como levantamentos da força de trabalho, censos e outros relatórios de pesquisas domiciliares e complementados com registros do LABORSTA, um laboratório de estatística da OIT. Para alguns países a fonte é administrativa ou resultado de análises de microdados, nos casos em que os dados tabulados não estavam disponíveis. Para a China foi criado um quadro síntese a partir de fontes variadas.
} 
A seguir, a figura 2 permite a visualização do arranjo espacial dessa regionalização proposta pelo estudo da OIT. Como pode ser visto, as regiões são formadas por agrupamentos de países com contiguidade fronteiriça, à exceção dos "países desenvolvidos". Estes se constituem basicamente por quatro núcleos: um no continente americano, um no europeu, um na Ásia e outro na Oceania. Vale ressaltar ainda, que esses aglomerados nacionais juntamente com o Oriente Médio, segundo as estimativas da OIT, representam principalmente consumidores do trabalho doméstico, enquanto os outros são tanto consumidores, quanto fornecedores (produtores) de força de trabalho (ILO, 2013).

Figura 2 - Distribuição do trabalho doméstico remunerado no mundo a partir de regionalização proposta pela Organização Internacional do Trabalho (OIT).

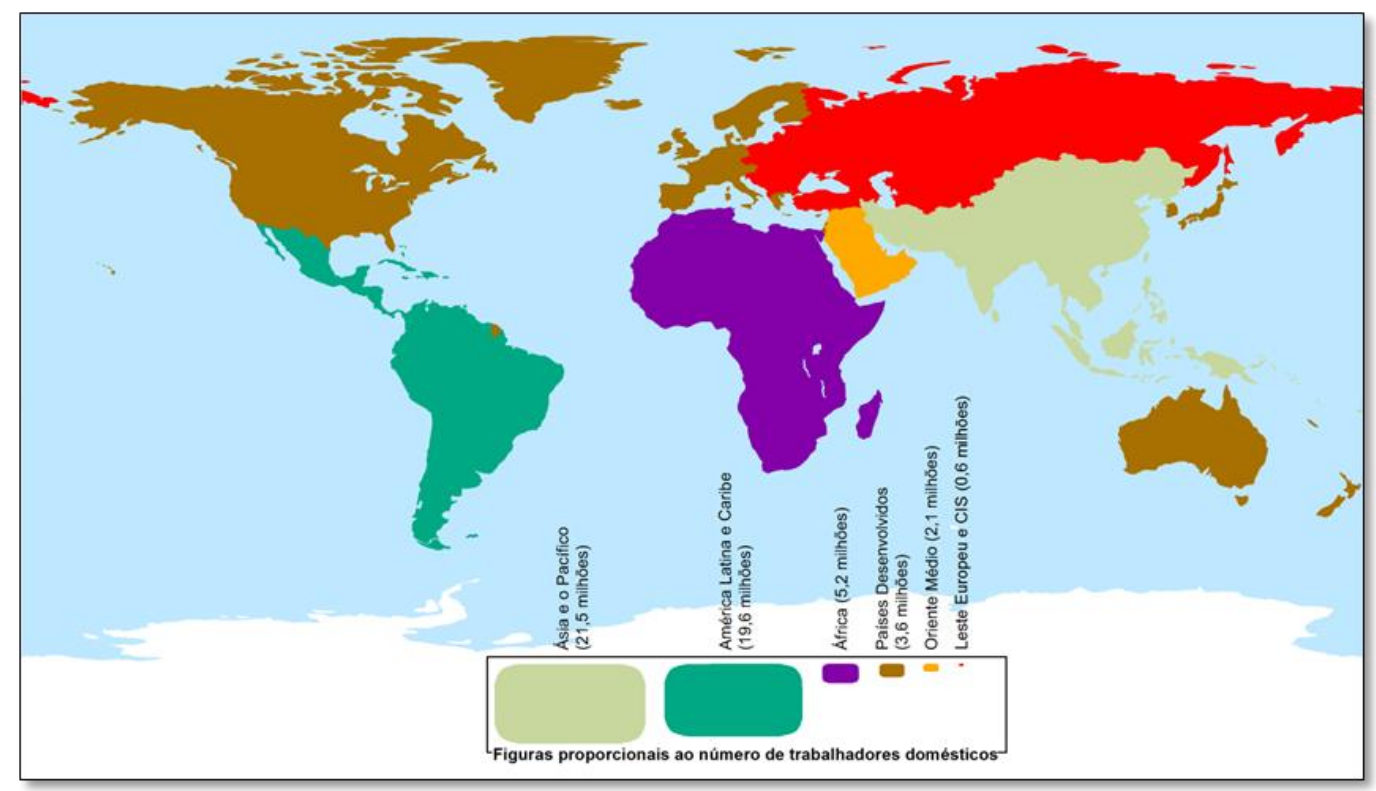

Nota: Os polígonos proporcionais na legenda representam o quantitativo de trabalhadores atuando em cada uma dessas regiões, segundo o estudo da OIT.

Fonte: Elaboração dos autores a partir de dados publicados em ILO (2013).

Especificamente quanto aos volumes de trabalhadores sobressaem-se as regiões da Ásia-Pacífico e da América Latina-Caribe, como fica evidente na legenda da figura 2. Tais regiões, segundo o levantamento, concentram respectivamente, $41 \%$ e $37 \%$ do total global (vide figura

Figura 3). Portanto, constituem-se os principais mercados tanto de produçãofornecimento de força de trabalho quanto de consumo da mesma. 
Figura 3 - Distribuição dos trabalhadores domésticos segundo sexo e regiões classificadas pela OIT, 2010.

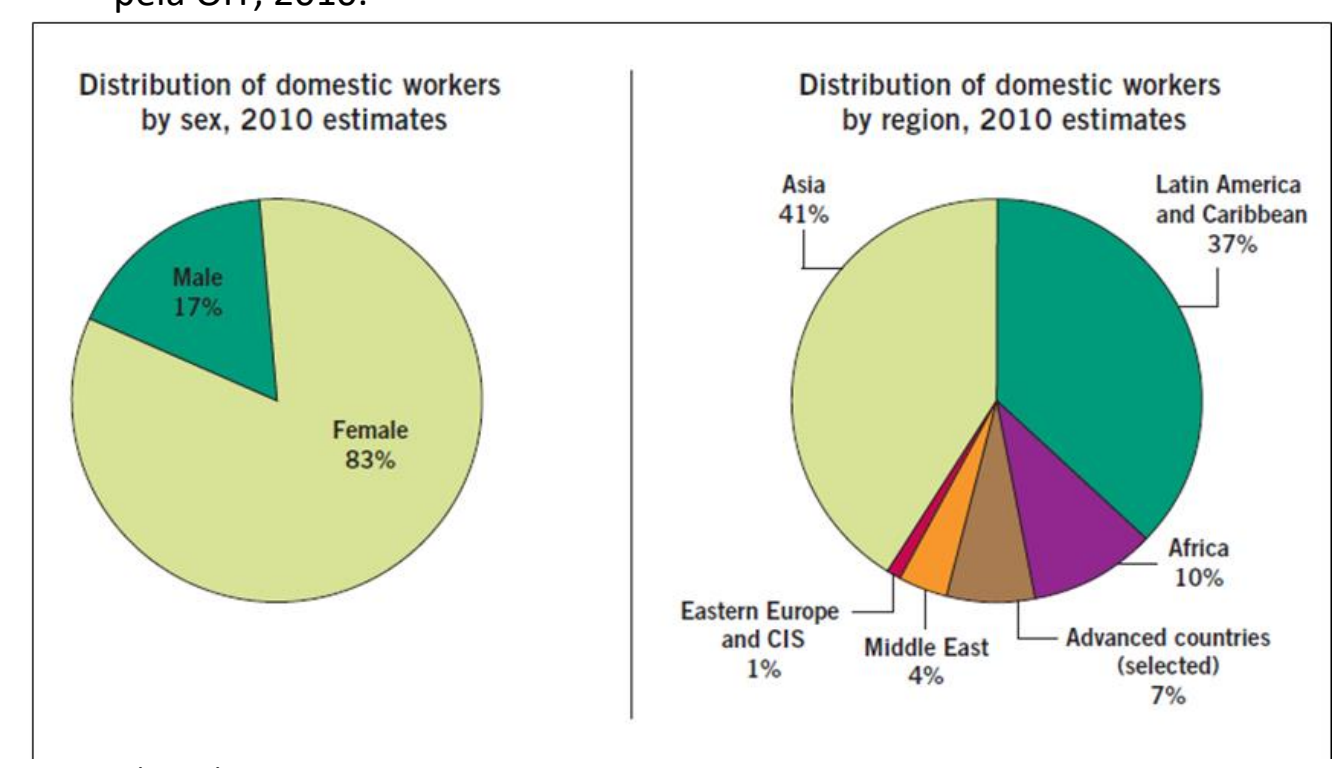

Fonte: ILO (2013).

$\mathrm{Na}$ "América Latina e Caribe" o contingente dos trabalhadores domésticos alcança a marca de 19.593.000, o que representa 37\% do total mundial. Esta região só fica atrás da Ásia, a qual abrange $41 \%$ dos trabalhadores domésticos. Mesmo assim, se considerado que essa última é desproporcionalmente o foco mais populoso do mundo, observa-se a maior importância relativa da região americana.

No mapa da figura 4 é possível perceber a distribuição geral dos trabalhadores domésticos entre os países da região. Nesse contexto, o Brasil destaca-se tanto como um dos mais importantes usuários de trabalho doméstico remunerado, como pode ser visto na variável "percentual de trabalhadores domésticos no total de trabalhadores", quanto também no volume de trabalhadores nos serviços domésticos. Veja que o círculo sobre o Brasil é especialmente o maior da região. 
Figura 4 - Distribuição da população de trabalhadores domésticos na Ámerica Latina e Caribe (países com 100 mil ou mais trabalhadores).

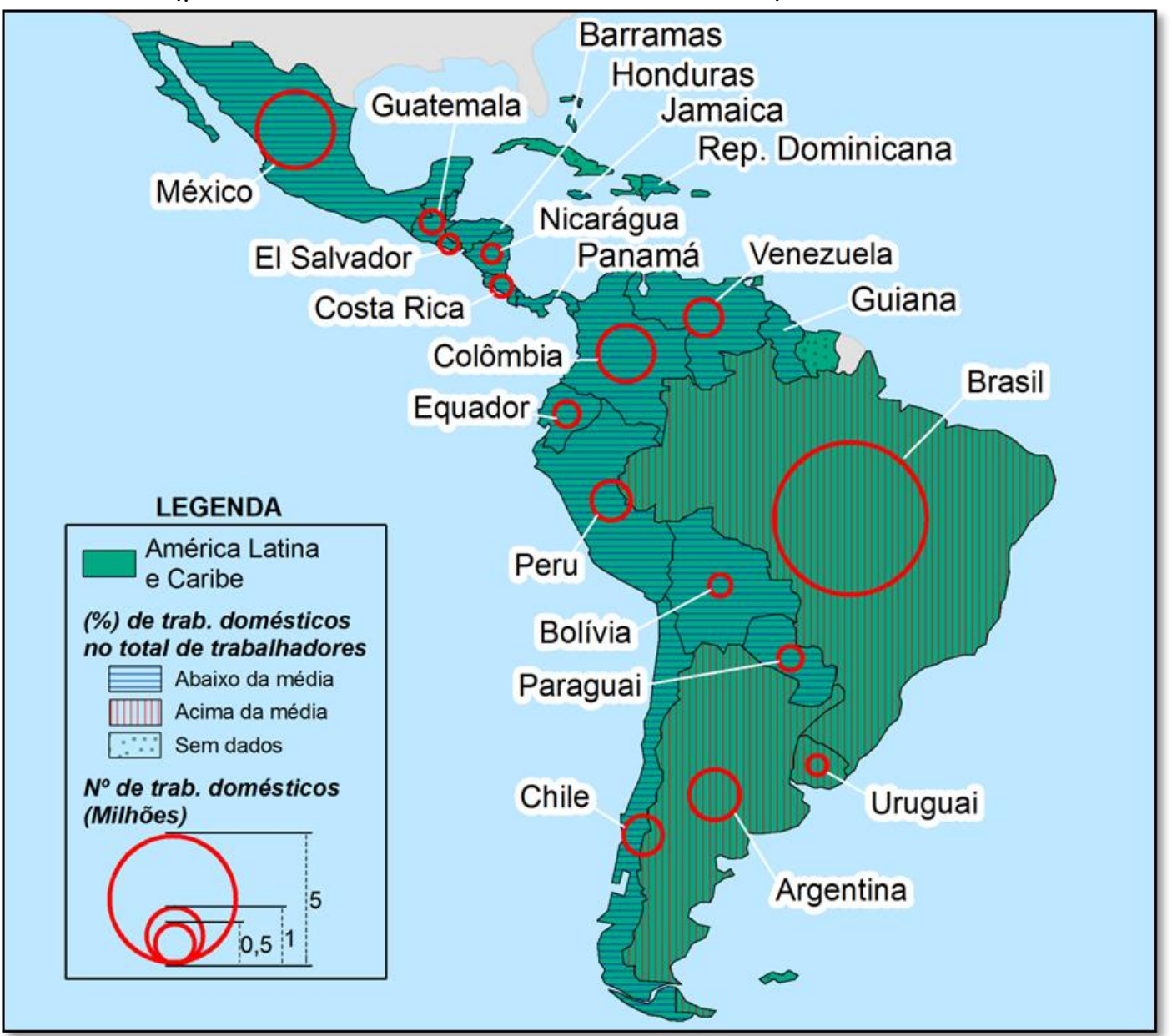

Fonte: Elaboração dos autores a partir de dados publicados em ILO (2013).

Quando considerado o volume por país, fica evidente a expressiva representatividade do trabalho doméstico remunerado brasileiro no Mundo. Pelas estimativas da OIT, a populosa China é o país com o maior contingente de trabalhadores doméstico, estimado em 9 milhões. O Brasil ocupa o segundo lugar, com um contingente próximo a 7 milhões. Em seguida vem a Índia, com 4 milhões e a Indonésia, as Filipinas e o México, cada um com algo em torno de 2 milhões de trabalhadores. Depois destes, com contingente superior a 1 milhão somente a África do Sul. Todos os demais países apresentaram quantitativo inferior a 1 milhão de trabalhadores ${ }^{4}$.

No que se refere à grande representatividade numérica da América Latina na

\footnotetext{
${ }^{4}$ No Apêndice II de ILO (2013) encontram-se dados por países referentes ao volume estimado de tralhadores doméstico por gênero, a participação percentual no total da força de trabalho, assim como a fonte dos dados e estimativas coletados por país. Importa lembrar que, conforme registrado no relatório da Organização, déficits de dados e informações podem ter subestimado alguns dos valores apresentados.
} 
população de trabalhadores doméstico do mundo, a OIT propõe algumas razões que podem explicá-la, dentre as quais levanta-se a hipótese de haver nexo entre o crescimento e o elevado contingente de trabalhadores domésticos na América Latina e Caribe, aos altos níveis de desigualdade de renda presentes na região ${ }^{5}$.

Outra hipótese levantada diz respeito às lacunas que os Estados da região apresentam no que se refere às políticas de conciliação entre trabalho e família, frente ao significativo aumento da participação da mulher no mercado de trabalho, assim como ao aumento da demanda por cuidados diante do crescente envelhecimento da população.

Neste ensaio, as reflexões desenvolvidas vão no sentido de colaborar com as discussões que estão no âmbito da segunda hipótese levantada pela OIT. O grande volume dos serviços domésticos no Brasil confirma que o país faz uso em larga escala dessa força de trabalho como estratégia de resolução da esfera reprodutiva da sociedade. As mudanças demográficas, mas principalmente a entrada maciça das mulheres no mercado de trabalho acentua esse uso, o que fica evidente tanto pelo crescimento do volume dos serviços domésticos, quanto pela sua representatividade no conjunto da força de trabalho nacional e especificamente feminina.

De acordo com a Pesquisa Nacional por Amostra de Domicílios Contínua (PNAD C IBGE), dos 6,5 milhões de pessoas ocupadas nos serviços domésticos no Brasil no ano de 2018, 93\% eram mulheres, superando a média mundial, que é de aproximadamente $80 \%$, segundo a OIT (ILO, 2013). Em 2018, 14\% do total de mulheres ocupadas exerciam essa atividade, o que significa a importância do trabalho doméstico remunerado para a população trabalhadora feminina nacional.

Apesar dessa configuração, o tema da reprodução social, apesar de atual, ainda tem pouca legitimidade e reconhecimento no país, ocupando pouco espaço na agenda púbica e no sistema de proteção social (MOSER; DAL PRÁ, 2016). Em parte, essa realidade ocorre em função da desvinculação do Estado e das empresas no que se refere aos enfrentamentos dos

\footnotetext{
${ }^{5}$ O objetivo não é testar o quanto tais hipóteses são mais ou menos adequadas a explicar o volume do trabalho doméstico no Brasil. Na verdade, entende-se que esses são fatores que somados a outros constroem os elementos que o determinam. Dessa forma, a problemática deve ser mediada pela reflexão que represente um esforço de apreensão das determinações mais gerais que incidem sobre formação sócio-histórica e econômica da América Latina, que particularizam tanto a produção e reprodução das desigualdades em seus países quando o enfrentamento das questões relacionadas ao atendimento das demandas vinculadas à reprodução social.
} 
impasses oriundos dos conflitos resultantes das tensões entre trabalho e vida familiar. Além disso, as questões relacionadas ao trabalho doméstico, tanto o que ocorre de forma remunerada, quanto não remunerada, não tem recebido significativa atenção da sociedade brasileira.

\section{Alguns elementos para a reflexão sobre reprodução social e o padrão predominante na sociedade brasileira}

$\mathrm{Na}$ ordem socioeconômica capitalista, sob o império da mercadoria, a sociedade moderna é a sociedade do trabalho produtor de valores de troca geradores de riqueza, a qual se produz socialmente para ser apropriada privadamente pelos donos dos meios de produção, os quais também são os que se apropriam da totalidade das mercadorias produzidas pelos trabalhadores (PEREIRA, 2015).

O caráter mítico ou fetichizado da produção de mercadorias faz com que as relações sociais entre os seres sociais adquiram a forma de relação entre coisas e o resultado dialético da sociedade erigida sob a produção de valores de troca "[...] é a convivência dual entre a produção de riqueza e miséria, de acumulação e privação, do possuidor e do despossuído" (ANTUNES, 2005, p. 72).

Esse processo de coisificação aliena e estranha o trabalhador tanto do processo de trabalho quanto do seu produto, sua finalidade, necessidade e uso. Sendo o processo de trabalho capitalista extremamente individualizador e atomizador, isola o trabalhador e aparta o mundo do trabalho das demais dimensões da vida, embora, paradoxalmente, o modo de ser do ser social encontre-se cada vez mais impactado e profundamente modificado pelo modo de produzir.

Essa condição representa consequências graves para a vida humana e sua síntese pode ser identificada no processo de despertencimento social, provocado pelo desenraizamento em relação à natureza. Pela constante artificialização da vida, os ritmos de trabalho e de vida estão cada vez mais desassociados aos ritmos naturais, em que "cotidianamente, os habitus no trabalho, que impregnaram a vida social - acesa, apressada e veloz - cristalizam tempos sociais incompatíveis com os biorritmos dos indivíduos, [...]" (FRANCO, 2011, p. 186).

Em consequência deste contexto contraditório de desenvolvimento e consolidação da sociabilidade capitalista, em que "quase toda a população transformou--se em empregada 
do capital" (BRAVERMAN, 1987, p. 342), ocorre uma importante cisão na vida social, a qual interessa particularmente para este ensaio: a separação entre o mundo do trabalho e o mundo da família. Ou seja, com o evolver da forma de produzir capitalista e o consequente desenvolvimento dos processos de urbanização e industrialização, com poucas exceções, a família deixou de ser reconhecida enquanto uma unidade produtiva, fosse para o autoconsumo ou para a realização de trocas comerciais. Assim,

[...] nasce uma família identificada como "instância privada", isenta de responsabilidades públicas e, ao mesmo tempo, com disponibilidade de recursos privados com base na criação e no controle de um capital privado. Em outras palavras, sem a obrigação de responder às consequências sociais e coletivas do próprio processo de circulação e de acumulação de capital; consequentemente, cortando os vínculos de reciprocidade. Isso marca uma assimetria entre as famílias detentoras do capital privado e as famílias que para essas trabalhavam. Essa separação provocou o estabelecimento de uma visão da família desvinculada do trabalho e das relações econômicas (MIOTO, 2015, p. 701).

Porém, o aprofundamento dos estudos sobre família, em especial movidos a partir dos anos 1960 e 1970, no contexto dos questionamentos feministas acerca do papel da mulher, assim como as mudanças demográficas registradas mundialmente nas últimas décadas e a entrada massiva da mulher no mercado de trabalho, vêm revelando a uma dimensão econômica e de valor estabelecida na relação entre o trabalho, a família e o mercado, no contexto da cisão entre a vida familiar e o mundo do trabalho: "[...] a família nuclear composta de homem, mulher e filhos, calcada na divisão sexual do trabalho - o 'male breadwinner model' - , não é apenas uma unidade social fundamental para a sociedade, mas é também uma unidade econômica de distribuição de bens e serviços [...]" (MIOTO, 2015, p. 701, grifo da autora).

Colabora na melhor apreensão desse debate considerar a separação entre esses "dois mundos", sob o ponto de vista da separação entre as esferas "produtiva" e "reprodutiva" da vida humana.

$\mathrm{Na}$ esfera da produção estariam compreendidas as atividades que delas resultam bens ou serviços com valor monetário e pelas quais se tem, também, um retorno monetário pela sua realização, o qual, no sistema capitalista, assume a forma predominante de salário.

Já a esfera da reprodução poderia ser compreendida enquanto o conjunto de ativos que "[...] produzem a força de trabalho - atividades que transformam matérias- -primas e 
mercadorias compradas com um salário, para manter, cotidianamente, o(a) trabalhador(a) e gerar a futura força de trabalho" (BORIS, 2014, p. 103).

Por sua vez, os ativos responsáveis pela reprodução da força de trabalho, não se resumem apenas ao recebimento do salário e seu consequente dispêndio para a aquisição dos valores de uso necessários para o sustento do trabalhador e de sua família. Envolvem, também, uma série de atividades que possibilitam que os mesmos sejam usados ou consumidos. Dessa maneira, a esfera reprodutiva congrega as atividades que são realizadas em prol da reprodução da vida, não somente da procriação, mas de todas as ações que garantam que as pessoas possam manter as suas próprias vidas, tanto do ponto de vista biológico quanto do bem-estar. Nas palavras de Singer (1979, p. 119), tais atividades seriam,

[...] a comida que tem que ser preparada, a louça que tem que ser lavada e seca, a roupa que tem que ser lavada, passada e ocasionalmente reparada, as peças os móveis e demais objetos [que] também tem que ser limpos, sem falar dos cuidados especiais que devem ser prestados a crianças pequenas, pessoas idosas e doentes. Tudo isso exige uma soma de esforços, de tempo e de trabalho não social considerável. A divisão de tarefas dentro da família do trabalhador - quem vende a capacidade de trabalho no mercado, quem cuida dos serviços domésticos, quem amplia sua capacidade de trabalho futura frequentando cursos - estabelece relações de produção entre marido e mulher, pais e filhos e entre estes e outros eventuais componentes do domicílio, que são essenciais para a reprodução da força de trabalho.

Já de acordo com de Mioto (2015, p. 704), “[...] uma das chaves importantes desse debate está no reconhecimento do trabalho no âmbito da reprodução, e não apenas no campo da produção". Isso significa considerar que existe um valor econômico no tempo dedicado às atividades reprodutivas, que são realizadas no interior das famílias - os afazeres domésticos e o cuidado com os familiares - pondo em relevo a necessidade da quantificação da produção doméstica, o que no Brasil parece ainda não ter grande relevo, já que,

[...] as concepções econômicas convencionais, assim como as estatísticas nacionais utilizadas para o desenho das políticas macroeconômicas, não consideram e nem contabilizam o universo da economia do cuidado não remunerado, devido ao fato de esta não estar orientada para o mercado. Como o fruto desse trabalho é praticamente invisível, ele também não é objeto de políticas públicas (GELINSKI; PEREIRA, 2005, p. 81).

Economistas, dentre outros especialistas, argumentam no sentido de demonstrar a necessidade de se contabilizar os ganhos produtivos que um país tem com o grande contingente de afazeres domésticos desenvolvidos nos lares pelas "donas de casa".

De acordo Gelinski e Pereira (2005), a Organização das Nações Unidas (ONU) 
apresentou a primeira metodologia de cálculo das Contas Nacionais ou System of National Accounts (SNA) em 1952. No Brasil, os esforços de criação do sistema de contas nacionais são de 1947, por meio do núcleo de economia da Fundação Getúlio Vargas. Mas, só em 1956, o Brasil dispôs, pela primeira vez, de um balanço geral da atividade econômica do país, a partir da adaptação ao SNA/1952 das estimativas da renda nacional a custo de fatores (GELINSKI; PEREIRA, 2005). Apesar dos esforços, segundo as autoras, os Sistemas de Contas Nacionais brasileiros são incompletos, uma vez que,

[...] omitem todo um universo de atividades fora do mercado e, portanto, parcela significativa da produção, tais como o trabalho não remunerado, o valor do tempo de lazer, os investimentos em capital humano e o meio ambiente (GELINSKI; PEREIRA, 2005, p. 79).

Melo, Considera e Di Sabbato (2007), afirmam que "os afazeres domésticos também contam" e demonstram o quanto esses afazeres representariam do Produto Interno Bruto (PIB) brasileiro se fossem contabilizados. Chegaram à conclusão de que as atividades valiam cerca de 11,2\% do PIB nacional no ano de 2006.

Outra dimensão do reconhecimento de que há trabalho ou valor agregado na esfera reprodutiva refere-se ao seu crescente processo de mercantilização nas sociedades. Isso ocorre de maneira diferenciada entre os países e envolve a participação de diversos atores sociais, o que evidencia que,

[...] a reprodução da força de trabalho depende, pois, tanto do montante do salário real, ou seja, da quantidade e qualidade dos valores de uso adquiridos no mercado, como dos bens e serviços 'domésticos' e 'estatais' de que o trabalhador e sua família podem dispor em cada momento (SINGER, 1979, p. 119).

A quantidade de trabalho ou de valor econômico agregado contido na esfera reprodutiva, portanto, está diretamente vinculada à redistribuição da riqueza socialmente produzida, ou a sua falta, nas diversas sociedades.

Conforme lembra Singer (1979), desde a promulgação da Poor Law na Inglaterra, o Estado participa diretamente da reprodução da força de trabalho, mediante transferências de recursos monetários sob a forma de pensões, aposentadorias, salário--família, auxílio a desempregados etc. e mediante a prestação de serviços principalmente no campo da educação, da assistência à saúde e do saneamento.

Em diversos países do capitalismo central, em função do desenvolvimento de modelos de Estado social inspirados pela lógica do welfare state ao longo do século XX, 
entende-se que as atividades reprodutivas não são responsabilidade apenas das famílias, mas, também, dos demais entes sociais, dentre os quais o Estado e as empresas. O engajamento dos vários agentes sociais permite a busca de soluções coordenadas, como, por exemplo: licenças para qualquer um dos pais, oferta de creches públicas ou de espaços criados pelas empresas para permitir que os pais possam estar mais próximos dos filhos, dentre outros (GELINSKI; PEREIRA, 2005; MOSER; DAL PRÁ, 2016).

Mas, no Brasil, esses provimentos sociais compartilhados não têm ocorrido substancialmente, complicando a situação das famílias, as quais convivem com os conflitos e tensões oriundas do atendimento das necessidades de reprodução social. Por meio dos impostos e demais contribuições sociais, as famílias brasileiras pagam duplamente o ônus de assumir, praticamente sozinhas, a responsabilidade pela reprodução da vida e da força de trabalho nacional.

Nos serviços públicos como creche, pré-escola e escola, apesar dos avanços nas últimas décadas, a oferta pelo Estado ainda é restrita e, sobretudo, precária, o que para as classes mais baixas no estrato de renda significa má ou nenhuma cobertura, em especial no que se refere às creches e pré-escolas. Para as classes mais abastadas a contratação na rede privada, que tem expandido como alternativa à precariedade do ensino público no país, tem sido a alternativa.

As empresas, por sua vez, tem tido pouco protagonismo na provisão de serviços e benefícios sociais, sendo esse substancialmente reduzido nas últimas décadas. As maiores provisões são ofertadas pelas grandes empresas, sem muitas vezes escapar ao assistencialismo e ao uso de discursos de benemerência e clientelismo no contexto da chamada responsabilidade socioempresarial.

Vê-se, portanto, o papel incipiente na prestação de serviços sociais por parte do Estado e do mercado na sustentação e compartilhamento das responsabilidades pelo provimento das demandas relacionadas à esfera reprodutivas no Brasil. É nesse sentido que,

[...] ao longo da história brasileira, costumes domésticos, têm dispensado estruturas de cuidados, essas da proteção social, de iniciativa pública e mesmo privada, daí seus outros sinais econômicos. Eles vêm permitindo, por séculos, economizar investimentos públicos em creches, cancelar ou adiar o projeto de escolas públicas em tempo integral de larga cobertura e, mesmo, regular a oferta de abrigo para pessoas doentes e idosas (COSTA, 2014, p. 778, grifo da autora).

Dessa maneira, o Brasil reproduz um padrão "familista" no que se refere às 
estratégias de conciliação entre vida produtiva e a reprodutiva, onde essas questões não comparecem como centrais na constituição do sistema público de proteção social ou na responsabilidade social e empresarial. A seguir poderá ser visto quais as estratégias, por sua vez, utilizadas pelas famílias, quais dilemas e contradição estão postos nesse processo.

\section{A centralidade do trabalho feminino e do trabalho doméstico remunerado diante das tensões entre a esfera produtiva e reprodutiva da vida social no Brasil}

Durante muito tempo as famílias brasileiras, puderam contar com o apoio de comunidade (vizinhos, parentes) na resolução das tensões entre trabalho e os cuidados com a família. Mas, as transformações na estrutura das famílias brasileiras põem em crise a alternativa da solidariedade baseada nos sistemas de ajuda tradicionais entre famílias e comunidades.

De acordo com Sorj, Fontes e Machado (2007, p. 580), entre os anos de 1981 e 2005 aumentou o número de famílias do tipo "unipessoal", "casal sem filhos" e "mulher chefe sem cônjuge e com filho". Ao mesmo tempo, houve uma diminuição das famílias do tipo "casal com filho e com parente" e "casal com filho", apesar desse último ainda ser o que predomina na organização da estrutura familiar brasileira.

Nesse sentido, uma mudança societária de grande importância para a esfera reprodutiva no Brasil é, hoje, a transição demográfica, que tem como uma repercussão direta o envelhecimento populacional. Segundo o Censo Demográfico de 2010, os idosos - pessoas de 60 anos ou mais - representa 10,8\% da população total do país. Em 1991 eram 7,3\% e as projeções apontam para a continuidade desse crescimento. O envelhecimento populacional aumenta a demanda por cuidados em uma fase avançada do ciclo de vida.

Por sua vez, a diminuição das taxas de fecundidade e de natalidade, dentre outras coisas, se reflete numa mudança na estrutura familiar, cuja principal característica é a diminuição do tamanho das famílias. Isso por um lado, representa uma menor demanda por cuidados com crianças, por outro, a diminuição na rede de solidariedade familiar.

Portanto, “[...] há evidências de que o apoio para responsabilidades domésticas e o cuidado estão cada vez menos disponíveis e mais problemáticos, principalmente em áreas urbanas" (RICOLDI, 2010, p. 38). As famílias, em suas formações diversificadas, tendem a ter maiores dificuldades de encontrar ajuda nos sistemas tradicionais, que se dão por meio da 
ajuda de parentes nas relações com a família extensa e com a vizinhança, embora ainda desempenhem papel importante, principalmente nas famílias monoparentais e mais empobrecidas (SORJ; FONTES; MACHADO, 2007).

Por outro lado, as mudanças recentes demarcadas pela forte inserção da mulher no mercado de trabalho agudizam as tensões geradas pela cisão entre o mundo do trabalho e a vida familiar, exigindo da sociedade novas estratégias de enfrentamento desse conflito.

Se as mulheres sempre trabalharam, o que se destaca nos dias de hoje é um significativo incremento das mulheres na população ativa, que na França, por exemplo, passou de um terço à metade em um século (HIRATA, 2016).

O Censo Demográfico do IBGE de 1950, registrou a participação de $13,6 \%$ das mulheres na População Economicamente Ativa (PEA). A partir de então, essa participação só cresceu, chegando a 49,9\%, de acordo com o Censo de 2010. Por outro lado, a participação masculina decresceu. Passou de $80,8 \%$ para $67,1 \%$ no mesmo período.

Diante da reflexão sobre as mudanças decorrentes da ampla participação da mulher no mundo do trabalho remunerado, Melo e Castilho (2009) elaboraram a seguinte questão: "Trabalho reprodutivo no Brasil: quem faz?" e chegaram à conclusão de que, "[...] são as mulheres (donas de casa e suas empregadas domésticas), com auxílio de algumas pessoas do sexo masculino. Este universo é naturalizado como feminino" (MELO; CASTILHO, 2009, p. 9).

Nas pesquisas domiciliares do IBGE a partir de 2001, foi introduzido um quesito sobre o número de horas dedicadas aos afazeres domésticos, o que permitiu novas avaliações sobre o equilíbrio entre trabalho e família por meio de estudos sobre a dedicação aos afazeres domésticos. Para o ano de 2005, “[...] o número médio de horas semanais trabalhadas pelas mulheres é 2,7 vezes o número de horas dedicadas pelos homens aos afazeres" (MELO; CASTILHO, 2009, p. 9).

A prevalência das mulheres nas atividades de reprodução aponta para o que Hirata e Kergoat (2007) denominam de "modelo tradicional", onde o homem tem o papel de provedor e à mulher é reservado o papel de assumir os cuidados com a família e os afazeres domésticos. As autoras apresentam, também, alguns novos arranjos em alternativa ao "modelo tradicional" a partir de práticas identificáveis nos núcleos familiares, embora ainda haja significativa prevalência do "tradicional".

O primeiro modelo é o de "conciliação", onde o papel do homem permanece inalterado como o de provedor e a mulher acumula além do papel de cuidadora do lar, 
também o de provedora. Nessa perspectiva, se reforça e naturaliza o opressivo e explorador padrão de dupla jornada de trabalho, vivenciado por milhões de mulheres no Brasil e ao redor do mundo, restando às mulheres arcarem com as "consequências" de sua entrada no mercado de trabalho.

A lógica desse modelo pressupõe que cabe às mulheres a responsabilidade de conciliar a vida familiar e profissional. Essa estratégia inspirou políticas públicas na Europa ${ }^{6} \mathrm{e}$ está na base das intervenções do Estado brasileiro na regulação do trabalho e na sua fragmentada atuação no sentido de proporcionar aos homens e mulheres com responsabilidades familiares possibilidades de resolução dos conflitos entre trabalho e família. O Estado regula apenas o segmento formalizado do mercado de trabalho, o que contempla apenas metade da população ocupada. Desse modo, a legislação trabalhista brasileira é pouco efetiva,

[...] para garantir a articulação entre trabalho e necessidades familiares ao longo de todas as etapas da vida familiar dos trabalhadores. Concentrando os benefícios apenas no momento inicial da procriação, a legislação não garante facilidades para que o trabalhador possa tratar das demandas familiares como um evento normal e regular da sua vida pessoal (SORJ; FONTES; MACHADO, 2007, p. 576).

O segundo modelo é o da "parceria", o qual pressupõe uma maior igualdade de estatutos sociais entre os sexos e o homem passa a assumir algumas tarefas domésticas, sendo tanto provedor quanto cuidador, assim como a mulher (HIRATA; KERGOAT, 2007). Esse modelo ainda é muito incipiente, mas as estatísticas sobre a participação nos afazeres domésticos apresentadas acima apontam para a sua existência.

O terceiro modelo é o da "delegação", o qual pressupõe um homem e uma mulher provedores, sendo as atividades de cuidado delegadas a terceiros, de forma remunerada ou não.

No Brasil, as estratégias de conciliação e delegação têm prevalecido, sempre sob a tutela preferencial de uma mulher. Contudo, as condições, características e repercussões sobre a vida das mulheres e das famílias ocorrem de maneira diferenciada, conforme as classes sociais.

O incremento feminino na população economicamente ativa não é homogêneo e

\footnotetext{
6 "Conciliação" vida familiar/vida profissional - política fortemente sexuada, visto que define implicitamente um único ator (ou atriz) dessa "conciliação": as mulheres (HIRATA; KERGOAT, 2007, p. 607).
} 
revela um fenômeno denominado por Bruschini e Lombardi (2000) e Hirata (2016) de "bipolarização do emprego feminino", fortemente ligado ao processo de escolarização das mulheres. Isso implica em que a divisão de classe entre as mulheres que entram no mercado de trabalho aponta para uma diversidade de estratégias possíveis às mulheres de cada polo, e seus respectivos companheiros, no que se refere ao contingenciamento das demandas entre vida familiar e vida profissional. Se somente é capaz de produzir quem está com as questões reprodutivas resolvidas de alguma forma (HIRATA; KERGOAT, 2007), tais resoluções se dão de maneiras diversas entre as classes sociais. Em outras palavras, a prevalência em muitos países do modelo de delegação se deve à,

[...] polarização do emprego das mulheres (HAKIM, 1996) e ao crescimento da categoria de profissões de nível superior e de executivas; elas têm ao mesmo tempo a necessidade e os meios de delegar a outras mulheres as tarefas domésticas e familiares [...]. É essa expansão dos empregos em serviços nos países capitalistas ocidentais, tanto desenvolvidos como semi-industrializados e em vias de desenvolvimento, como o Brasil (SORJ, 2004), que oferecem novas "soluções" para o antagonismo entre responsabilidades familiares e profissionais (HIRATA; KERGOAT, 2007, p. 604-605).

Estariam em um polo uma minoria de mulheres executivas, profissionais intelectuais de nível superior, relativamente bem remuneradas, em postos de responsabilidade e prestígio social (médicas, advogadas, juízas, arquitetas, engenheiras, jornalistas, professoras universitárias, pesquisadoras, publicitárias etc.). O outro polo, majoritário, seria constituído de "[...] mulheres em setores menos valorizados socialmente e com salários mais baixos relativamente, dentre os quais serviços domésticos" (HIRATA, 2016, p. 3). Segundo análise da autora, como consequência política dessa polarização tem-se uma "[...] exacerbação das desigualdades sociais e antagonismos, tanto entre mulheres e homens, quanto entre as próprias mulheres" (HIRATA, 2016, p. 3). No caso do Brasil,

[...] o serviço doméstico remunerado tem um papel importante na absorção das mulheres de menor escolaridade e sem experiência profissional no mercado de trabalho. As migrantes rurais-urbanas têm nessas atividades "o caminho de socialização na cidade [...] o abrigo, a comida, a casa e a família" [Castro (1982)], porta de entrada para o mercado de trabalho urbano, as mulheres iniciavam esse trabalho nas casas de famílias a título de "ajuda" Provavelmente, a oferta e os baixos salários pagos a essas trabalhadoras possibilitaram que as mulheres dos estratos de renda médios e altos ingressassem no mercado de trabalho nas últimas décadas, sem que a sociedade criasse em contrapartida serviços coletivos de creches, escolas em tempo integral, atividades que diminuíssem em parte os encargos familiares com a socialização das crianças. Como as mulheres pobres não têm voz no cenário político, restaram-lhes as soluções improvisadas para a guarda dos seus próprios filhos, sem interferência do Estado. Como essas mulheres sempre trabalharam, seja no eito ou 
na senzala, a novidade atual é o exercício do trabalho fora de casa das mulheres da classe média (MELO, 1998, p. 6, grifo da autora).

Para o caso brasileiro isto é agravado pelas enormes desigualdades existentes entre classes sociais: "dados sugerem que as classes altas e médias são as mais cuidadas no Brasil" (ENGEL; PEREIRA, 2015, p. 8).

A partir dos dados da Pesquisa de Orçamento Familiar do IBGE para os anos de 2008 e 2009, Sorj e Fontes (2012), concluíram que as famílias de classes altas contam com auxílio externo para a manutenção de atividades de cuidado com a casa e com as pessoas em uma porcentagem de 51,7\%. Se as famílias tiverem filhos menores que 6 anos o percentual aumenta para $73 \%$. Já nos lares de menor renda a porcentagem reduz-se para 2,2\% e aumenta somente para $2,4 \%$ no caso de famílias com filhos menores que 6 anos.

Assim, a mais ampla estratégia de reprodução social das mulheres de classe média e alta no Brasil é a contratação de serviços domésticos. Contudo, diante das ausências nas prestações de serviços sociais por parte do Estado e das empresas, parece razoável a constatação de Costa (2014, p. 780), segundo a qual no Brasil, “[...] segmentos sociais médios de diferentes níveis de renda, mesmo os que se declaram pobres, pagam por esse trabalho valores de muitas variações para atividades também muito diversas". Corroboram para essa constatação os dados de Bruschini e Ricoldi (2009), que demonstram as dificuldades enfrentadas pelas mães trabalhadoras de baixa renda, para as quais uma das estratégias é, por exemplo, pagar, mesmo que irrisoriamente, a alguém, normalmente da família ou da vizinhança, para dispensar os cuidados com suas próprias casas e em especial às crianças, idosos ou pessoas portadoras de necessidades especiais.

Diante dessas constatações ganha relevo nesse debate o volume de pessoas que se ocupam nos serviços domésticos remunerados, evidenciando a realidade de que o uso desses serviços representa o principal pilar do sistema de reprodução no Brasil. Os dados sobre trabalho doméstico remunerado corroboram tais constatações.

\section{Considerações finais}

As insuficiências do sistema de proteção social brasileiro, sobretudo no que se refere aos serviços públicos sobrecarregam as famílias, com repercussões diferenciadas sobre as mesmas, conforme a posição de classes que cada uma ocupa. Dessa maneira, prevalece no 
país um padrão "familista" que se utiliza da conciliação e da delegação como principais estratégias de contingenciamento das demandas advindas da relação entre vida produtiva e reprodutiva, com prevalência das responsabilidades recaídas sobre o trabalho das mulheres. Por sua vez, a contratação de serviços domésticos remunerados passa a ser o pilar que sustenta o sistema de reprodução social no Brasil.

Portanto, pode-se concluir que, no Brasil, a esfera reprodutiva está amplamente alicerçada sobre soluções de foro privado-familiar. Se ainda se conta de forma incipiente com a participação do Estado e das empresas, no que se refere aos serviços e equipamentos sociais cabe, então, às famílias o desenvolvimento de estratégias. Pela hierarquia de gênero, a incumbência da resolução do conflito trabalho e vida familiar ainda permanece, sob diversas formas, uma responsabilidade eminentemente feminina. Predominantemente, os homens se eximem e as mulheres conciliam e delegam, de forma integral ou parcial. Muitas vezes no exercício dessas estratégias são utilizados mecanismos informais de apoio, sobretudo recorrendo-se a familiares, vizinhos ou outros sujeitos do convívio sociofamiliar.

Contudo, é na contratação de serviços domésticos remunerados onde se encontra a maior estratégia de delegação das tarefas afeitas ao mundo da reprodução social. Os números referentes aos serviços domésticos remunerados no país corroboram essas constatações. Mesmo nesse caso, as mulheres continuam ocupando o papel central na responsabilidade pela resolução dos conflitos entre vida familiar e mundo do trabalho. Mesmo que para as que se empregam nesse universo, o mundo doméstico apenas se sobreponha, com todas as marcas do patriarcalismo marcante na sociedade brasileira.

\section{Referências}

ANTUNES, Ricardo. O caracol e sua concha: ensaios sobre a nova morfologia do trabalho. São Paulo: Boitempo, 2005.

BORIS, Eileen. Produção e reprodução, casa e trabalho. Tempo Social: Revista de Sociologia da USP, São Paulo, v. 26, n. 1, p. 101-121, 2014.

BRAVERMAN, Harry. Trabalho e capital monopolista: a degradação do trabalho no século XX. 3. ed. Rio de Janeiro: LTC, 1987.

BRUSCHINI, Cristina; LOMBARDI, Maria Rosa. A bipolaridade do trabalho feminino no Brasil Contemporâneo. Cadernos de Pesquisa, São Paulo, n. 110, p. 67-104, jul. 2000. 
BRUSCHINI, Maria Cristina Aranha; RICOLDI, Arlene Martinez. Família e trabalho: difícil conciliação para mães trabalhadoras de baixa renda. Cadernos de Pesquisa, São Paulo, v. 39, n. 136, p. 93-123, jan./abr. 2009.

COSTA, Francilene Soares de Medeiros. A diarização do trabalho doméstico remunerado no Brasil e os dilemas atuais da (des)proteção social. 2017. 208 f. Tese (Doutorado em Geografia) - Universidade Estadual Paulista, Presidente Prudente, 2017.

COSTA, Suely Gomes. Conforto, proteção social e emprego doméstico (Brasil e Região Fluminense, 1960-2000). Serviço Social e Sociedade, São Paulo, n. 120, p. 767-794, out./dez. 2014.

ENGEL, Cíntia; PEREIRA, Bruna Cristina Jaquetto. A organização social do trabalho doméstico e de cuidado: considerações sobre gênero e raça. Revista Punto Género, Santiago, n. 5, p. 424, nov. 2015.

FRANCO, Tânia. Alienação do trabalho: despertencimento social e desenraizamento em relação à natureza. Caderno $C R H$, Salvador, v. 24, n. 1, p. 171-191, 2011.

GELINSKI, Carmen Rosario Ortiz Gutierrez; PEREIRA, Rosângela Saldanha. Mulher e trabalho não remunerado. Mulher e Trabalho, Porto Alegre, v. 5, p. 79-87, 2005.

HIRATA, Helena. Mulheres brasileiras: relações de classe, de "raça" e de gênero no mundo do trabalho. Confins: Revista Franco-brasileira de Geografia, São Paulo, n. 26, 2016.

HIRATA, Helena; KERGOAT, Danièle. Novas configurações da divisão sexual do trabalho. Cadernos de Pesquisa, São Paulo, v. 37, n. 132, p. 595-609, set./dez. 2007.

ILO - INTERNATIONAL LABOR ORGANIZATION. Domestic workers across the world: global and regional statistics and the extent of legal protection. Geneva: ILO, 2013.

ILO - INTERNATIONAL LABOR ORGANIZATION. Social protection for domestic workers: key policy trends and statistics. Geneva: ILO, 2016. (Social Protection Policy Papers, n. 16).

ILO. INTERNATIONAL LABOR ORGANIZATION. Global Wage Report 2010/11: Wage policies in times of crisis (Geneva). Geneva: ILO/International Labour Office, 2010.

MELO, Hildete Pereira de. O serviço doméstico remunerado no Brasil: de criadas a trabalhadoras. Texto para Discussão, Rio de Janeiro, n. 565, 1998.

MELO, Hildete Pereira de; CASTILHO, Marta. Trabalho reprodutivo no Brasil: quem faz? Revista de Economia Contemporânea, Rio de Janeiro, v. 13, n. 1, p. 135-158, jan./abr. 2009.

MELO, Hildete Pereira de; CONSIDERA, Claudio Monteiro; DI SABBATO, Alberto. Os afazeres domésticos contam. Economia e Sociedade, Campinas, v. 16, n. 3, p. 435-454, dez. 2007.

MIOTO, Regina Célia Tamaso. Política social e trabalho familiar: questões emergentes no debate contemporâneo. Serviço Social e Sociedade, São Paulo, n. 124, p. 699-720, out./dez. 2015. 
MOSER, Liliane; DAL PRÁ, Keli Regina. Os desafios de conciliar trabalho, família e cuidados: evidências do "familismo" nas políticas sociais brasileiras. Textos \& Contextos, Porto Alegre, v. 15, n. 2, p. 382-392, ago./dez. 2016.

OIT - ORGANIZAÇÃO INTERNACIONAL DO TRABALHO. Convenção e recomendação sobre trabalho decente para as trabalhadoras e os trabalhadores domésticos. Brasília: OIT, 2011.

OIT - ORGANIZAÇÃO INTERNACIONAL DO TRABALHO. Manual de capacitação e informação sobre gênero, raça, pobreza e emprego: guia para o leitor. Brasília: OIT, 2005.

PEREIRA, Potyara Amazoneida Pereira. Degradação do trabalho e políticas sociais "ativas" na ordem neoliberal: aproximações ao caso brasileiro. Revista SER Social, Brasília, v. 17, n. 37, p. 455-480, jul./dez. 2015.

RICOLDI, Arlene Martinez. A noção de articulação entre trabalho e família e políticas de apoio. Mercado de Trabalho, Brasília, n. 42, p. 37-43, 2010.

SINGER, Paul. Economia política do trabalho. 2. ed. São Paulo: Hucitec, 1979.

SORJ, Bila e FONTES, Adriana. O care como regime estratificado: implicações de gênero e classe social". In. HIRATA, Helena e GUIMARÃES, Nadya Araújo (Orgs.): Cuidado e cuidadoras: as várias faces do trabalho de care, p.103-116. São Paulo: Atlas, 2012.

SORJ, Bila; FONTES, Adriana; MACHADO, Danielle Carusi. Políticas e práticas de conciliação entre família e trabalho no Brasil. Cadernos de Pesquisa, São Paulo, v. 37, n. 132, p. 573-594, set./dez. 2007. 